\title{
Recovery of preoperative absolute knee extension and flexion strength after $\mathrm{ACL}$ reconstruction
}

\author{
Ramana Piussi ${ }^{1,2}$, Daniel Broman ${ }^{1}$, Erik Musslinder ${ }^{1}$, Susanne Beischer ${ }^{1,3}$, Roland Thomeé ${ }^{1,3}$ and \\ Eric Hamrin Senorski ${ }^{1,3,2^{*}}$ (D)
}

\begin{abstract}
Background: The recovery of muscle function after an Anterior Cruciate Ligament (ACL) reconstruction is most commonly reported as limb-to-limb differences using the Limb Symmetry Index (LSI), which is not free from limitations. The purpose of this study was to compare the proportion of patients who recover their Preoperative Absolute Muscle Strength (PAMS) 8 and 12 months after ACL reconstruction with the proportion of patients who recover their symmetrical knee strength. A secondary aim was to assess the relationship between psychological Patient-Reported Outcomes (PROs) and recovering PAMS at 8 and 12 months after ACL reconstruction and rehabilitation.

Method: Preoperative, 8- and 12-month results from quadriceps and hamstring strength tests and PROs for 117 patients were extracted from a rehabilitation registry. Individual preoperative peak torques from strength tests were compared with results from the 8- and 12-month follow-ups respectively. Patients were defined as having recovered their PAMS upon reaching $90 \%$ of their preoperative peak torque for both quadriceps and hamstring strength. Patients were defined as having recovered their LSI upon reaching a value $\geq 90 \%$ when comparing the results for their injured knee with those of their healthy knee. Correlations between the recovery of PAMS and PROs at 8 and 12 months were analyzed.

Results: There was no difference in the proportion of patients who recovered their PAMS compared with patients who recovered their $\mathrm{LSI}$. In all, 30\% and 32\% of the patients who recovered their LSI had not recovered their PAMS at 8 months and 12 months respectively. In the patients who had recovered their PAMS, 24\% and 31\% had not recovered their symmetrical LSI at 8 months and 12 months respectively. There was no significant correlation between the recovery of PAMS and psychological PROs.
\end{abstract}

Conclusion: The use of both PAMS and LSI provides more detailed information on the recovery of muscle strength after ACL reconstruction. The recovery of PAMS was not correlated with psychological traits, which implies that both PROs and PAMS are important when evaluating patients after ACL reconstruction.

Trial registration: This trial was not registered.

Keywords: Knee, Anterior cruciate ligament, Evaluation, Limb symmetry index

\footnotetext{
* Correspondence: eric.hamrin.senorski@gu.se

'Sportrehab Sports Medicine Clinic, Stampgatan 14, SE-411 01 Gothenburg, Sweden

${ }^{3}$ Unit of Physiotherapy, Department of Health and Rehabilitation, Institute of Neuroscience and Physiology, Sahlgrenska Academy, University of Gothenburg, Box 455, SE-405 30 Gothenburg, Sweden

Full list of author information is available at the end of the article
}

(c) The Author(s). 2020 Open Access This article is licensed under a Creative Commons Attribution 4.0 International License, which permits use, sharing, adaptation, distribution and reproduction in any medium or format, as long as you give appropriate credit to the original author(s) and the source, provide a link to the Creative Commons licence, and indicate if changes were made. The images or other third party material in this article are included in the article's Creative Commons licence, unless indicated otherwise in a credit line to the material. If material is not included in the article's Creative Commons licence and your intended use is not permitted by statutory regulation or exceeds the permitted use, you will need to obtain permission directly from the copyright holder. To view a copy of this licence, visit http://creativecommons.org/licenses/by/4.0/. The Creative Commons Public Domain Dedication waiver (http://creativecommons.org/publicdomain/zero/1.0/) applies to the data made available in this article, unless otherwise stated in a credit line to the data. 


\section{Background}

An Anterior Cruciate Ligament (ACL) injury is a common sports-related knee injury [11]. After a rupture of the ACL, a period of rehabilitation consisting of neuromuscular and strength training is warranted [27]. Post-injury rehabilitation is important since not all patients benefit from early surgery, sometimes referred to non-copers [19]. Furthermore, post-injury rehabilitation might lead to patients resuming pre-injury activity without the need for surgery, and might restore some knee stability in patients, showing better outcomes after ACL reconstruction [27]. After an ACL reconstruction and individualised rehabilitation, an important goal for most patients and healthcare providers is a safe return to sport (RTS) [33]. Approximately 60\% of patients RTS within 2 years of ACL reconstruction, of which $30 \%$ go on to suffer a second ACL injury [3], or meniscal or cartilage injuries [15]. Passing batteries of strength and hop tests before RTS can reduce this risk of re-injury after ACL reconstruction [4, 15]. Furthermore, specific cut-offs for poor Patient-Reported Outcomes (PROs), reflecting a lower psychological readiness to return to sport, appear to correlate with a second ACL injury [20]. For this reason, evaluating patients' muscle function and psychological well-being after ACL reconstruction could be beneficial to clinical practice.

Burgi et al. [8] reported that the time from reconstruction is the most frequently used criterion in the literature for the RTS decision-making process after ACL reconstruction. However, using the results of muscle function tests and psychological PROs as the criterion for determining a safe RTS is becoming more common [2, 4, 12, 22, 25, 36]. The results of muscle function tests after ACL injury, regardless of treatment, are often reported as limb-to-limb differences, i.e. the proportional recovery of the injured limb compared with the uninjured limb, using the Limb Symmetry Index (LSI) $[1,2]$. This is, however, not free from limitations, which include the fact that patients commonly suffer from loss of strength in the uninjured limb, as well as the injured limb, entailing the risk of overestimating recovery [30]. In these cases, using the LSI suggests symmetrical muscle function based on bilateral weakness, thereby increasing the risk of sending an athlete back to sport too early [38]. Accordingly, whether the use of the LSI as an RTS criterion is stringent enough has been questioned [7, 38]. Adding absolute strength measurements as outcomes after ACL reconstruction could possibly provide more detailed information on the recovery of strength [31].

The recovery of symmetrical strength (LSI) has been linked with higher knee-related self-efficacy [23, 29] and a higher readiness to RTS $[9,37]$ measured with PROs, and although novel attempts have been made to determine the effectiveness of preoperative absolute muscle strength (PAMS) as an RTS criterion, the relationship between the recovery of PAMS and psychological PROs remains unclear. Gokeler et al. [14] found that patients who underwent ACL reconstruction did not perform as well as healthy controls in hop tests 7 months after surgery, although they achieved symmetrical LSI in hop tests. In addition, Wellsandt et al. [38] showed that, after ACL reconstruction, patients struggled to achieve preoperative results in a battery of tests. Therefore, a better understanding of the relationship between PAMS and psychological PROs is warranted and could further help clinicians determine the recovery of patients after ACL reconstruction.

The purpose of this study was to compare the proportion of patients who recover their preoperative absolute muscle strength (PAMS) 8 and 12 months after ACL reconstruction with the proportion of patients who recover their symmetrical knee strength. In addition, the study aimed to assess the relationship between psychological PROs and recovering PAMS at 8 and 12 months after ACL reconstruction and rehabilitation.

\section{Method}

The present study used data from Project ACL, extracted on 13 July 2019. Project ACL is a rehabilitation-specific registry located in Sweden for patients with an ACL injury. The data consist of the results of muscle function tests and PROs, which are collected prospectively, starting with ACL injury or reconstruction as a baseline and thereafter at predefined follow-ups: 10 weeks, 4, 8, 12, 18 and 24 months, 5 years and every fifth year thereafter. The registry has previously been described in detail $[6,16]$ and ethical approval has been obtained from the Regional Ethical Review Board in Gothenburg, Sweden (registration numbers: 265-13, T023-17).

\section{Patients}

All patients with a unilateral ACL injury treated with primary ACL reconstruction and rehabilitation were considered eligible for inclusion to this study. Patients were excluded after having recorded more than one ACL injury, not having performed strength tests preoperatively and not participating at both the 8 - and the 12-month follow-ups after ACL reconstruction.

\section{Strength tests}

Quadriceps and hamstring peak torque were measured concentrically with an isokinetic dynamometer (Biodex System 4; Biodex Medical System, Shirley, New York, USA) [32] at an angular speed of $90^{\circ}$ /second. Quadriceps and hamstring strength testing with the Biodex is reliable when it comes to measuring isokinetic muscle strength, Intraclass Correlation Coefficient $=0.95$ [10]. Quadriceps and hamstring strength (peak torque) was assessed unilaterally in a seated position, (approximatively $110^{\circ}$ of hip flexion) with shoulders, waist, thigh and distal lower leg 
being strapped and arms crossed over the chest. The centre of the knee joint was aligned to the centre of movement axis of the dynamometer at $90^{\circ}$ of knee flexion, while at rest. Knee extension (quadriceps) peak torque was measured from $90^{\circ}$ to $0^{\circ}$ of flexion, while knee flexion (hamstring) peak torque was measured from $0^{\circ}$ to $90^{\circ}$ of flexion. After a standardized warm-up (Fig. 1), 3 maximum repetitions of knee extension, instantly followed by knee flexion, were performed with $30 \mathrm{~s}$ of rest between each repetition. Patients were offered the opportunity of doing an additional fourth repetition if they felt they could do one more. The peak torque in Newton / meters was used for analysis.

\section{Patient-reported outcomes}

The PROs used in this study were the Knee Self-Efficacy Scale (K-SES), future subscale (K-SES future) and the ACL Return to Sport after Injury scale (ACL-RSI).

The K-SES was developed to measure knee-related selfefficacy in patients with an ACL injury [28]. The original scale has good reliability $(\mathrm{ICC}=0.75)$ and good validity [28]. The subscale future of the K-SES consists of 4 questions where patients rate from 0 (not at all certain) to 10 (very certain) how certain they feel about their knee in the future. The results from each question are added together and divided by four to obtain a mean score for each patient. The maximum score is 10 and reflects the highest future perceived knee-related self-efficacy. The preoperative scores for the K-SES $S_{\text {future }}$ were used for analysis in this study. The future subscale of the K-SES was chosen, as it has been shown to predict the recovery of LSI 12 months after an ACL reconstruction [29].

The ACL-RSI was chosen since it is considered to have high methodological quality for patients with an ACL injury [12]. The ACL-RSI has good homogeneity (Cronbach's alpha $=0.95$ ) and good validity to assess psychological readiness to RTS [35]. In this study, the 12 -item version was used. The scale is graded from 0 to 10 , where 0 reflects the lowest readiness to RTS and 10 the highest [34, 35]. The responses from each item are added together to obtain a total score (range 0-120).
Data from the ACL-RSI were analyzed for the 8- and 12-month follow-ups.

\section{Outcomes}

The recovery of PAMS was the primary outcome of this study. The greatest preoperative peak torque for quadriceps and hamstring strength recorded from any limb from each individual patient was used as a reference for individual recovery. Preoperative peak torque for quadriceps and hamstrings for each individual patient were compared with the patient's quadriceps and hamstring peak torque at the 8- and 12-month follow-up respectively. Patients were defined as having recovered their PAMS upon reaching $90 \%$ of their preoperative peak torque for both quadriceps and hamstring strength.

The proportion of patients that had recovered their PAMS was compared with the proportion of patients that had recovered their symmetrical muscle strength (defined as LSI $\geq 90 \%$, which is considered consensus for recovered symmetrical muscle strenght after ACL injury and reconstruction [18]). Upon failing to recover their PAMS, a further analysis was carried out in order to determine which strength test the individual patient had not passed.

The correlations between the recovery of PAMS and ACLRSI scores at 8 and 12 months and the preoperative scores on the K-SES $S_{\text {future }}$ were analyzed as secondary outcomes.

\section{Statistics}

Statistical analyses were performed with the Statistical Product and Service Solutions (IBM Corp. Released 2017. IBM SPSS Statistics for Windows, Version 25.0. Armonk, NY: IBM Corp.). The Chi-Square test was used to compare the proportion of patients that had recovered their PAMS and LSI respectively. The Chi-Square test was used to compare the proportion of patients who did not recover the different parameter of PAMS, that is, quadriceps or hamstring strength. For all proportions, 95\% confidence intervals (CI) were provided. The point biserial correlation was used in the correlation analyses of recovery of PAM and PROs. Correlation coefficients

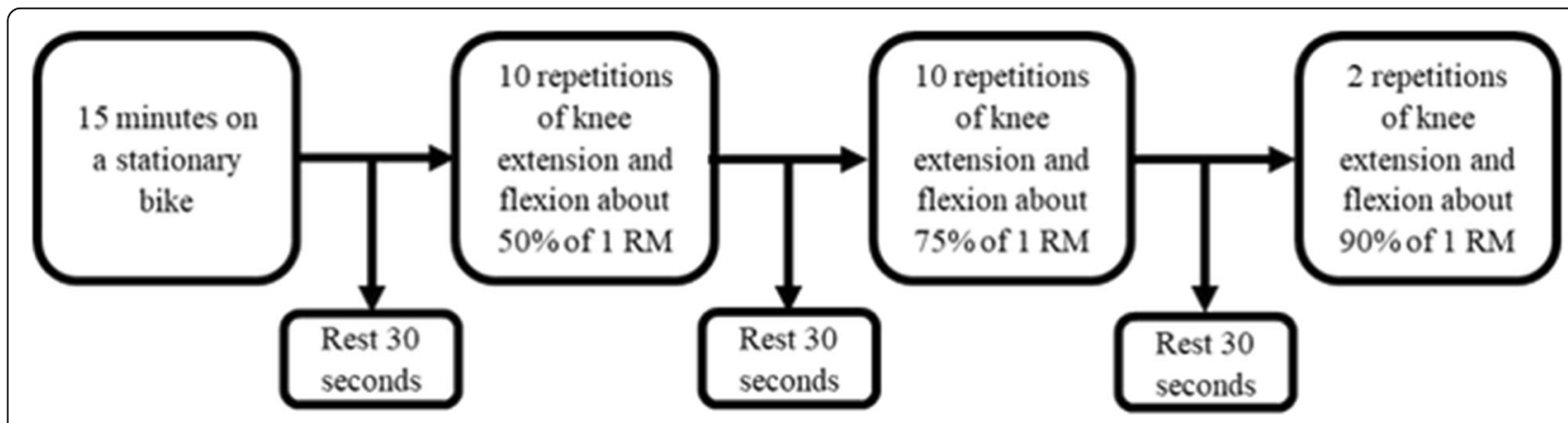

Fig. 1 Standardized warm-up procedure 
were defined as weak $(\mathrm{r}=0.00-0.39)$, moderate $(\mathrm{r}=$ $0.40-0.69)$, strong $(r=0.70-0.89)$ and very strong $(r=$ 0.90-1.00) [24]. A significance level of $95 \%$ was used.

\section{Results}

A total of 117 patients (men 33\%) were included in the study (Fig. 2).

The patients were $30 \pm 12$ years old on average at the time of ACL reconstruction. Most patients (91\%) received a hamstring tendon autograft (Table 1).

In all, 56\% (CI 47-66\%) of patients had pre-surgery LSI values $\geq 90 \%$. Further, $45 \%$ (CI 36-54\%) of patients recovered LSI, and $42 \%$ (CI 41-60\%) recovered PAMS at 8 months. At the 12 months follow up, 50\% (CI 33-51\%) of patients recovered LSI and 50\% (40-59\%) recovered PAMS. There was no difference in the proportion of patients who recovered their LSI or PAMS, at either 8 or 12 months after ACL reconstruction (Fig. 3).

In all, 30\% (CI 18-44\%) and 32\% (CI 20-45\%) of the patients who recovered their LSI had not recovered their PAMS at 8 months and 12 months, respectively. In the patients who had recovered their PAMS, 24\% (CI 13$38 \%$ ) and 31\% (CI 19-43\%) had not recovered their symmetrical LSI at 8 months and 12 months respectively.

There was no significant correlation between either the recovery of PAMS and ACL-RSI (8 months, $\mathrm{r}=0.001 ; 12$ months, $r=0.066$ ) or PAMS and K-SES future (8 months, $r=0.086 ; 12$ months, $r=0.049$ ).

In patients who had recovered their LSI but had not recovered their PAMS, the most common reason was not having recovered their absolute strength for hamstrings at the 12-month follow-up ( $27 \%$ of patients had not recovered, $p=0.001$ ) (Table 2).

\section{Discussion}

The main finding in this study was that there was no difference in the proportion of patients who had recovered their PAMS compared with patients who recovered their LSI 8 and 12 months after ACL reconstruction. Furthermore, there was no significant correlation between the recovery of PAMS and psychological readiness for RTS or future knee-related self-efficacy. As a result, psychological status, reported with PROs, and the recovery of PAMS appear to cover two different dimensions of patient recovery. In addition, our results indicated that patients who recover their LSI, but not their PAMS, most frequently fail to recover their preoperative hamstring strength 12 months after ACL reconstruction (27\% versus 11\% for quadriceps, $p=0.001$ ).

Despite the similar proportion of patients recovering their PAMS and LSI (45\% and $42 \%$ at 8 months, $50 \%$ in

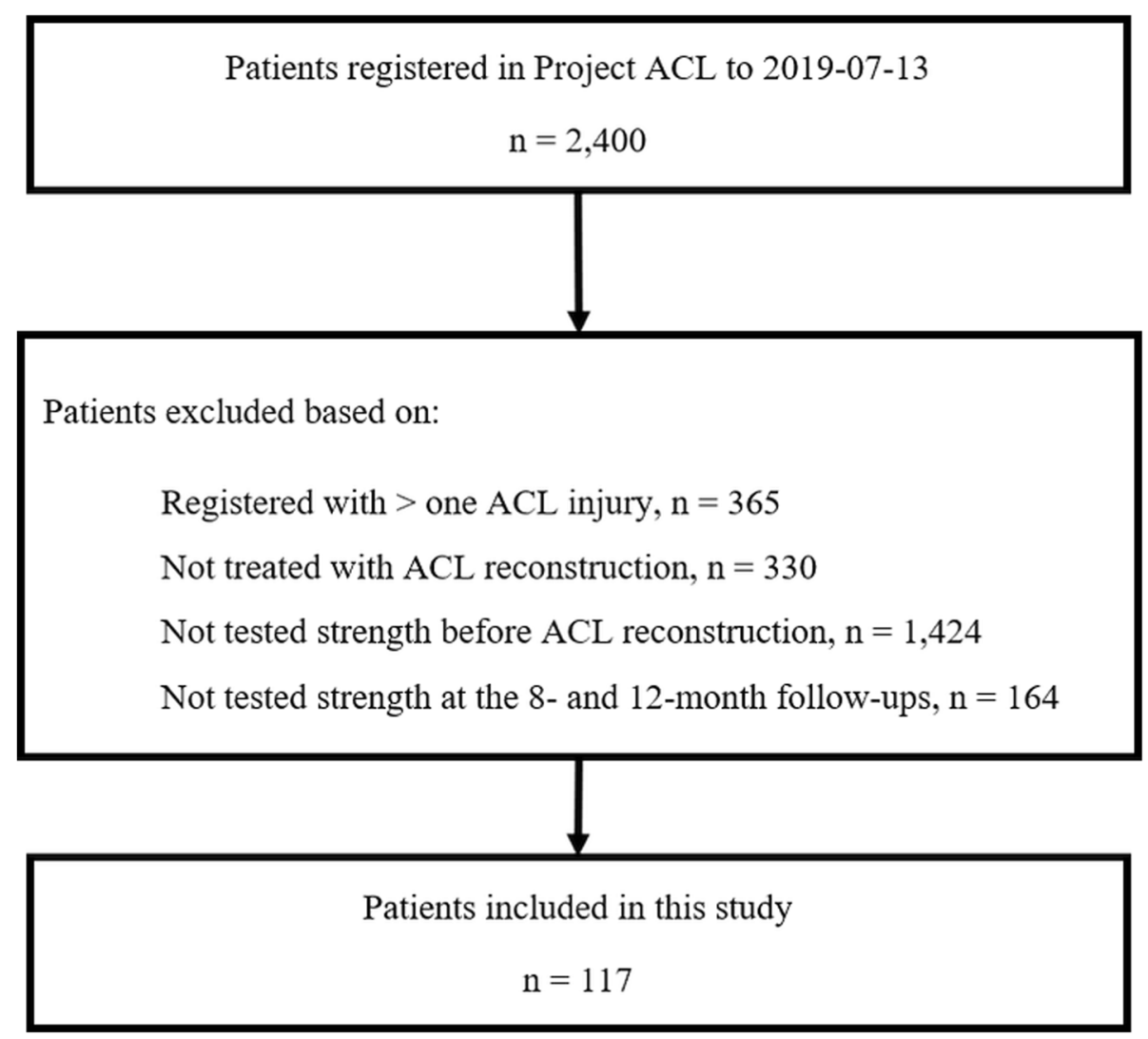

Fig. 2 Flowchart of included and excluded patients 
Table 1 Patient demographics, means and standard deviations

\begin{tabular}{llll}
\hline & Total & Men & Women \\
\hline Patients, n (\%) & $117(100)$ & $39(33)$ & $78(77)$ \\
Age, years & $29.8 \pm 11.7$ & $32.3 \pm 12.3$ & $28.5 \pm 11.3$ \\
Weight, kg & $71 \pm 13.7$ & $85 \pm 17.1$ & $65 \pm 11.1$ \\
Height, cm & $173 \pm 9.9$ & $183 \pm 6.1$ & $168 \pm 6.9$ \\
BMl, kg/height cm ${ }^{2}$ & $24 \pm 3.2$ & $26 \pm 6.2$ & $23 \pm 3.1$ \\
$\begin{array}{l}\text { Tegner, median } \\
\text { (min-max) }\end{array}$ & $8(2-10)$ & $8(3-10)$ & $8(2-10)$ \\
Graft choice & & & \\
$\quad$ Hamstring, n (\%) & $90.6 \%$ & $89.7 \%$ & $91.0 \%$ \\
$\quad$ Patellar, n (\%) & $6.8 \%$ & $10.3 \%$ & $5.1 \%$ \\
$\quad$ Other, n (\%) & $2.6 \%$ & - & $3.9 \%$ \\
\hline
\end{tabular}

$\mathrm{cm}$ centimeters; $\mathrm{kg}$ kilograms; $n$ number; Tegner Tegner Activity Scale

both groups at 12 months), there were differences in terms of which individual patients recover their PAMS and LSI. At the 12-month follow-up, about one third of the patients who had recovered their LSI had not recovered their PAMS and, conversely, about one third of the patients who had recovered their PAMS had not recovered their LSI. These results infer that approximately one third of patients who recover their symmetrical muscle strength are weaker than before the ACL reconstruction and that about one third of patients who recover their absolute muscle strength do not have symmetrical muscle strength. The main reason for not recovering PAMS was not having recovered preoperative hamstring strength. It is known that harvesting the hamstring tendon as an autograft results in hamstring strength deficits, [5] which likely contributed to the present results. This is not the first study to compare preoperative absolute strength after ACL reconstruction. Wellsandt et al. [38] investigated 70 patients 6 months after ACL reconstruction and reported that only about $30 \%$ recovered their pre-surgery absolute strength. Differences in time to follow-ups and definitions of PAMS make comparisons of the present study with the study by Wellsandt et al. [38] difficult. However, Wellsandt et al. [38] reported that approximately one in three patients who recovered their symmetry (LSI) did not recover their preoperative muscle strength, which is in line with the results of the present study. Both lower levels of symmetry in the quadriceps and hop tests, [15] and of absolute muscle strength, [17] can increase the risk of primary and secondary ACL injury. The results of the present study suggest that PAMS and LSI provide two different aspects of recovery. For this reason, adding the assessment of PAMS can be a useful complement when determining the recovery of patients treated with ACL reconstruction. However, future research is needed to confirm the role played by PAMS in secondary ACL injury reduction.

Since the recovery of PAMS has not been studied to the same extent as LSI, there is no clear consensus on how to define PAMS and which threshold to use to define recovery. Defining a recovery of PAMS by using $\geq$ $90 \%$ as a cut-off may be too low. Normally, an ACL injury is followed by a period of inactivity, which might lead to the loss of thigh and calf muscle mass and strength [13]. It may therefore be easier for patients to recover preoperative strength that is lower than the muscle strength they actually possessed at the time of injury. Additionally, the muscle strength that the patient possessed at the time of injury might not have been sufficient, as stronger muscles in lower extremities provide protection from primary ACL injury [21]. In order to

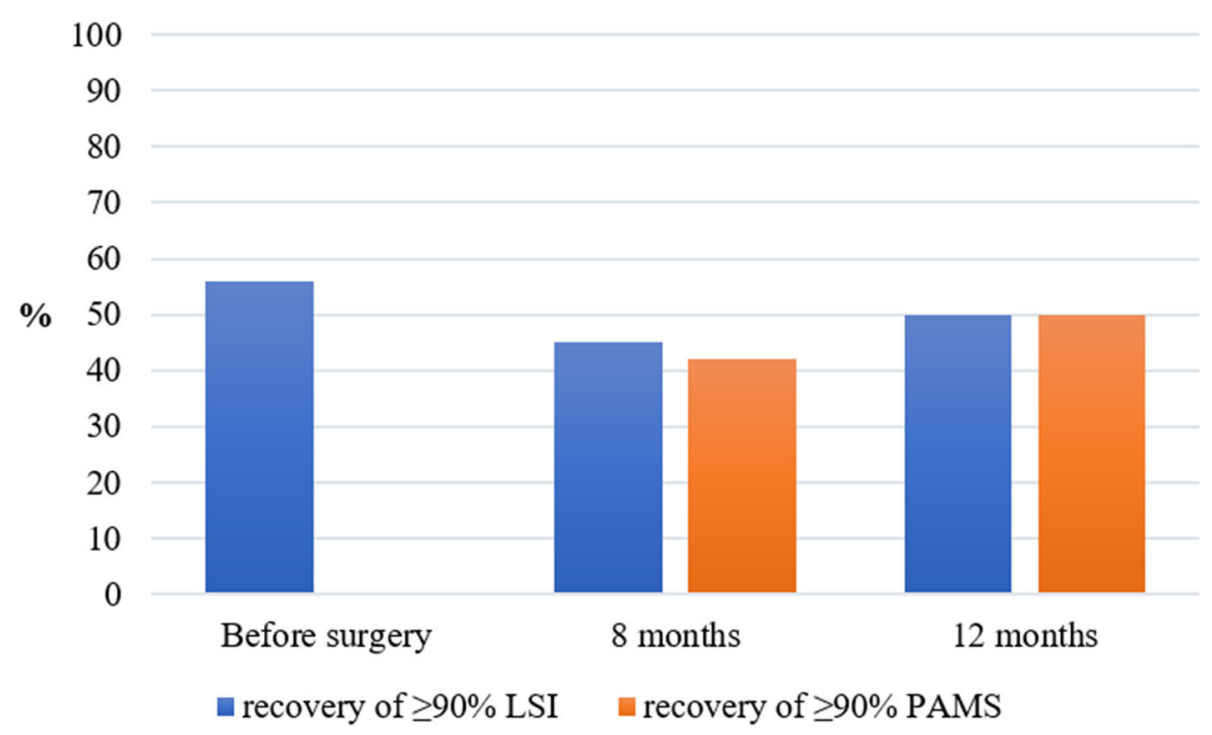

Fig. 3 Proportion of patients recovering their Limb Symmetry Index and Preoperative Absolute Muscle Strength 
Table 2 Numbers and proportions of patients recovering their LSI but not recovering their PAMS

\begin{tabular}{lllll}
\hline $\mathbf{n}$ (\%) & Recovered LSI & Not recovered PAMS quadriceps & Not recovered PAMS hamstrings & $\boldsymbol{p}$ value + \\
\hline 8 months & $56(45 \%)(\mathrm{Cl} 36-54 \%)$ & $6(11 \%)(\mathrm{Cl} 5-19 \%)$ & $12(22 \%)(\mathrm{Cl} 7-23 \%)$ & 0.056 \\
12 months & $59(50 \%)(\mathrm{Cl} 33-51 \%)$ & $7(11 \%)(\mathrm{Cl} 2-12 \%)$ & $16(27 \%)(\mathrm{Cl} 9-28 \%)$ & 0.001
\end{tabular}

$n$ number; PAMS Preoperative Absolute Muscle Strength; + , Chi Square test, $\mathrm{Cl}$ Confidence Interval

reduce the risk of subsequent ACL injuries, PAMS cutoff values higher than $>90 \%$ should be considered.

\section{Limitations}

The availability of data to determine PAMS is one limitation of this study. Many patients are enrolled in Project ACL after being treated with an ACL reconstruction. In the over 2000 patients available for inclusion, 1424 (58\%) had not tested their strength preoperatively. Another limitation of our study concerns pre-operative rehabilitation. We do not know whether patients enrolled in this study performed pre-operative rehabilitation or not, or the quality of their rehabilitation. A further limitation might be the preoperative loss of strength in the injured limb [13]. In the present study, we accounted for this limitation by taking the highest preoperative peak torque for quadriceps and hamstring strength recorded from any limb, for each patient, as a reference for recovery, regardless of whether it was taken from the injured limb or the uninjured limb. Another limitation relates to the method used for strength testing (seated isokinetic dynamometer). The isokinetic dynamometer measures knee extensors and knee flexors concentric peak torque at an angular velocity of $90 \%$ from a seated position and might therefore not reflect the full complexity of knee extensors and knee flexors muscle cooperation when performing a standing sport task in motion.

In our cohort, $77 \%$ of the patients $(N=78)$ were women. This is somewhat higher compared with the general population of patients with ACL injuries in Sweden, where 46\% are women and $54 \%$ are men [11]. It is not known why more women had tested their strength before ACL reconstruction in the cohort, which limits the generalizability of our results. However, a recent systematic review [26] reported no between-sex differences in the results of strength testing expressed as the LSI for hamstrings and quadriceps in patients after an ACL reconstruction. The results were based on 8 studies, where no study reported significant differences between the sexes in strength testing expressed as the LSI.

In addition, the patients included in this study, as well as in Project ACL, are a population with a generally high level of physical activity, with a median of 8 on the Tegner Activity Scale, which is equivalent to basketball, handball and triple jump. The results may therefore not be applicable to a population with lower physical activity levels or to patients who have not undergone ACL reconstruction. It should also be noted that $90 \%$ of the patients in the present study underwent ACLreconstruction using hamstring-graft which can explain the difficulty of recovering hamstring strength compared to quadriceps strength [5].

\section{Conclusion}

There was no difference in the proportion of patients who recovered their PAMS compared with their LSI, although, in approximately one third of the cases, patients who recovered symmetry had not recovered their preoperative absolute muscle strength and vice versa. The use of both preoperative absolute muscle strength and symmetrical muscle strength therefore provides more details relating to the recovery of muscle strength after ACL reconstruction. The recovery of PAMS was not correlated with psychological traits, which implies that both PROs and PAMS are important when evaluating patients after ACL reconstruction.

\section{Abbreviations}

ACL: Anterior Cruciate Ligament; ACL-RSI: ACL Return to Sport after Injury scale; K-SES: Knee Self-Efficacy Scale; LSI: Limb Symmetry Index; N: Number; PAMS: Preoperative Absolute Muscle Strength; PROs: Patient-reported

Outcomes; RM: Repetition Maximum; RTS: Return to Sport

\section{Acknowledgments}

The authors acknowledge Christoffer Thomeé for technical support of the Project ACL database.

\section{Authors' contributions}

Authors RT, EHS and SB contributed to the design of Project ACL and all the included methods and follow-ups that have made this specific study possible Authors RP, EM, DB and EHS are responsible for drafting the manuscript and contributed substantially to the research question and the analysis of data. All the authors have made major contributions by critically revising the manuscript for important intellectual content. All the authors have read and approved the final version of the manuscript.

\section{Funding}

Open Access funding provided by Gothenburg University Library.

\section{Availability of data and materials}

The dataset used and/or analyzed during the current study are available from the corresponding author in response to a reasonable request.

\section{Ethics approval and consent to participate}

Ethical approval was obtained from the Regional Ethical Review Board in Gothenburg, Sweden (registration numbers: 265-13, T023-17). Upon registration in Project $A C L$, patients sign a written consent for their data to be used for further analysis.

Consent for publication

Not applicable.

Competing interests

The authors declare that they have no competing interests to declare. 


\section{Author details}

'Sportrehab Sports Medicine Clinic, Stampgatan 14, SE-411 01 Gothenburg, Sweden. ${ }^{2}$ Sahlgrenska Sports Medicine Center, Gothenburg, Sweden. ${ }^{3}$ Unit of Physiotherapy, Department of Health and Rehabilitation, Institute of Neuroscience and Physiology, Sahlgrenska Academy, University of Gothenburg, Box 455, SE-405 30 Gothenburg, Sweden.

Received: 2 September 2020 Accepted: 22 November 2020 Published online: 10 December 2020

\section{References}

1. Abrams GD, Harris JD, Gupta AK, et al. Functional performance testing after anterior cruciate ligament reconstruction: a systematic review. Orthop J Sport Med. 2014;2(1):2325967113518305.

2. Almangoush A, Herrington L. Functional performance testing and patient reported outcomes following $A C L$ reconstruction: a systematic scoping review. Int Scholar Res Notice. 2014;2014:613034.

3. Ardern CL, Taylor NF, Feller JA, Whitehead TS, Webster KE. Sports participation 2 years after anterior cruciate ligament reconstruction in athletes who had not returned to sport at 1 year: a prospective follow-up of physical function and psychological factors in 122 athletes. Am J Sports Med. 2015;43(4):848-56.

4. Ashigbi EYK, Banzer W, Niederer D. Return to sport Tests' prognostic value for Reinjury risk after anterior cruciate ligament reconstruction: a systematic review. Med Sci Sports Exerc. 2020;52(6):1263-71.

5. Aune AK, Holm I, Risberg MA, Jensen HK, Steen H. Four-strand hamstring tendon autograft compared with patellar tendon-bone autograft for anterior cruciate ligament reconstruction. A randomized study with twoyear follow-up. Am J Sports Med. 2001;29(6):722-8.

6. Beischer S, Hamrin Senorski E, Thomeé C, Samuelsson K, Thomeé R. Young athletes return too early to knee-strenuous sport, without acceptable knee function after anterior cruciate ligament reconstruction. Knee Surg Sport Traumatol Arthroscopy. 2018;26(7):1966-74.

7. Benjaminse A, Holden S, Myer GD. ACL rupture is a single leg injury but a double leg problem: too much focus on 'symmetry' alone and that's not enough! Br J Sports Med. 2018;52(16):1029-30.

8. Burgi $\mathrm{CR}$, Peters $\mathrm{S}$, Ardern $\mathrm{CL}$, et al. Which criteria are used to clear patients to return to sport after primary $A C L$ reconstruction? A scoping review. $\mathrm{Br}$ J Sports Med. 2019;53(18):1154-61.

9. Burland JP, Kostyun RO, Kostyun KJ, Solomito M, Nissen C, Milewski MD. Clinical outcome measures and return-to-sport timing in adolescent athletes after anterior cruciate ligament reconstruction. J Athl Train. 2018;53(5):442-51.

10. Feiring DC, Ellenbecker TS, Derscheid GL. Test-retest reliability of the biodex isokinetic dynamometer. J Orthop Sport Phy Ther. 1990;11(7):298-300.

11. Forssblad M. Svenska Korsbandsregister årsrapport. 2019. https://www. aclregister.nu/media/uploads/Annual\%20reports/rapport_2019.pdf.

12. Gagnier JJ, Shen Y, Huang H. Psychometric properties of patient-reported outcome measures for use in patients with anterior cruciate ligament injuries: a systematic review. JBJS Rev. 2018;6(4):e5.

13. Gardinier ES, Manal K, Buchanan TS, Snyder-Mackler L. Gait and neuromuscular asymmetries after acute anterior cruciate ligament rupture. Med Sci Sports Exerc. 2012;44(8):1490-6.

14. Gokeler A, Welling W, Benjaminse A, Lemmink K, Seil R, Zaffagnini S. A critical analysis of limb symmetry indices of hop tests in athletes after anterior cruciate ligament reconstruction: a case control study. Orthop Traumatol Surg Res. 2017;103(6):947-51.

15. Grindem H, Snyder-Mackler L, Moksnes H, Engebretsen L, Risberg MA. Simple decision rules can reduce reinjury risk by $84 \%$ after $\mathrm{ACL}$ reconstruction: the Delaware-Oslo ACL cohort study. Br J Sports Med. 2016;50(13):804-8

16. Hamrin Senorski E, Samuelsson K, Thomee C, Beischer S, Karlsson J, Thomee R. Return to knee-strenuous sport after anterior cruciate ligament reconstruction: a report from a rehabilitation outcome registry of patient characteristics. Knee Surg Sports Traumatol Arthrosc. 2017;25(5):1364-74.

17. Kuh D, Bassey EJ, Butterworth S, Hardy R, Wadsworth ME. Grip strength, postural control, and functional leg power in a representative cohort of British men and women: associations with physical activity, health status, and socioeconomic conditions. J Gerontol A Biol Sci Med Sci. 2005;60(2):224-31.

18. Lynch AD, Logerstedt DS, Grindem H, et al. Consensus criteria for defining 'successful outcome' after ACL injury and reconstruction: a Delaware-Oslo ACL cohort investigation. Br J Sports Med. 2015;49(5):335-42.
19. Maffulli N, Oliva F. Coper Classification Early After ACL Rupture Changes With Progressive Neuromuscular and Strength Training and Is Associated With 2Year Success: Letter to the Editor. Am J Sport Med. 2019;47(11):Np64-np65.

20. McPherson AL, Feller JA, Hewett TE, Webster KE. Psychological readiness to return to sport is associated with second anterior cruciate ligament injuries. Am J Sports Med. 2019;47(4):857-62.

21. Nessler T, Denney L, Sampley J. ACL injury prevention: what does research tell us? Curr Rev Musculoskeletal Med. 2017;10(3):281-8.

22. O'Connor RF, King E, Richter C, Webster KE, Falvey ÉC. No relationship between strength and power scores and anterior cruciate ligament return to sport after injury scale 9 months after anterior cruciate ligament reconstruction. Am J Sports Med. 2020;48(1):78-84.

23. Piussi R, Beischer S, Thomeé R, Hamrin SE. Superior knee self-efficacy and quality of life throughout the first year in patients who recover symmetrical muscle function after ACL reconstruction. Knee Surg Sports Traumatol Arthrosc. 2020;28(2):555-67.

24. Schober P, Boer C, Schwarte LA. Correlation coefficients: appropriate use and interpretation. Anesth Analg. 2018;126(5):1763-8.

25. Smith A, Capin J, Zarzycki R, Snyder-Mackler L. Athletes with bone-patellar tendon bone autograft for $\mathrm{ACL}$ reconstruction were months slower to meet rehabilitation milestones and return to sport criteria than athletes with hamstring tendon autograft or soft tissue allograft: secondary analysis from the ACL-SPORTS trial. J Orthop Sports Phys Ther. 2019;50:1-28.

26. Tan SH, Lau BP, Khin LW, Lingaraj K. The importance of patient sex in the outcomes of anterior cruciate ligament reconstructions: a systematic review and meta-analysis. Am J Sports Med. 2016;44(1):242-54.

27. Thoma LM, Grindem H, Logerstedt D, et al. Coper classification early after anterior cruciate ligament rupture changes with progressive neuromuscular and strength training and is associated with 2-year success: the DelawareOslo ACL cohort study. Am J Sports Med. 2019;47(4):807-14.

28. Thomee P, Wahrborg P, Borjesson M, Thomee R, Eriksson BI, Karlsson J. A new instrument for measuring self-efficacy in patients with an anterior cruciate ligament injury. Scand J Med Sci Sports. 2006;16(3):181-7.

29. Thomeé $P$, Währborg P, Börjesson M, Thomeé R, Eriksson B, Karlsson J. Selfefficacy of knee function as a pre-operative predictor of outcome 1 year after anterior cruciate ligament reconstruction. Knee Surg Sport Traumatol Arthroscopy. 2008;16(2):118-27.

30. Thomee R, Neeter C, Gustavsson A, et al. Variability in leg muscle power and hop performance after anterior cruciate ligament reconstruction. Knee Surg Sport Traumatol Arthroscopy. 2012;20(6):1143-51.

31. Trulsson A. Additional perspectives on 'ACL rupture is a single leg injury but a double leg problem ... '. Br J Sports Med. 2019;53(16):993-5.

32. Undheim MB, Cosgrave C, King E, et al. Isokinetic muscle strength and readiness to return to sport following anterior cruciate ligament reconstruction: is there an association? A systematic review and a protocol recommendation. Br J Sports Med. 2015;49(20):1305-10.

33. van Melick N, van Cingel RE, Brooijmans F, et al. Evidence-based clinical practice update: practice guidelines for anterior cruciate ligament rehabilitation based on a systematic review and multidisciplinary consensus. Br J Sports Med. 2016;50(24):1506-15.

34. Webster KE, Feller JA. Development and validation of a short version of the anterior cruciate ligament return to sport after injury (ACL-RSI) scale. Orthop J Sport Med. 2018;6(4):2325967118763763.

35. Webster KE, Feller JA, Lambros C. Development and preliminary validation of a scale to measure the psychological impact of returning to sport following anterior cruciate ligament reconstruction surgery. Phys Ther Sport. 2008;9(1):9-15.

36. Webster KE, Hewett TE. What is the Evidence for and Validity of Return-toSport Testing after Anterior Cruciate Ligament Reconstruction Surgery? A Systematic Review and Meta-Analysis. Sport Med. 2019:49(6):917-29.

37. Webster KE, Nagelli CV, Hewett TE, Feller JA. Factors associated with psychological readiness to return to sport after anterior cruciate ligament reconstruction surgery. Am J Sports Med. 2018;46(7):1545-50.

38. Wellsandt E, Failla MJ, Snyder-Mackler L. Limb symmetry indexes can overestimate knee function after anterior cruciate ligament injury. J Orthop Sport Phys Ther. 2017:47(5):334-8.

\section{Publisher's Note}

Springer Nature remains neutral with regard to jurisdictional claims in published maps and institutional affiliations. 